\title{
UM OLHAR SOBRE A CULTURA
}

\author{
Elenilton Vieira Godoy" \\ Vinício de Macedo Santos*
}

RESUMO: Este artigo tem como objetivo discutir significados de cultura e a sua obrigatória presença para se pensarem as questões relacionadas a algumas ideias, tais como, poder, resistência e política, que não nascem nas teorias de currículo, mas que foram por elas apropriadas. Destaca-se a importância da cultura para discutirem-se as questões da contemporaneidade, a partir da premissa de que a cultura é formada por um conjunto de sistemas de significados que dão sentido às ações humanas, sejam elas as nossas ou as demais, possibilitando o entendimento de que qualquer ação social é cultural e que, por isso, as práticas sociais que expressam, comunicam e produzem significados são práticas de significação, discursivas. Para isso, recorre-se às ideias de autores que investigam a temática do currículo para justificar a relevância da cultura nas discussões que tangenciam a educação, a escola, as disciplinas escolares e as relações de poder, resistência e política. Palavras-chaves: Práticas de significação. Cultura. Currículo. Poder.

\footnotetext{
*Doutor em Educação pela Universidade de São Paulo. Atuou como docente em Matemática na Educação Básica na rede particular de ensino de São Paulo. Atualmente é professor do Centro Universitário da FEl, do Centro Universitário Fundação Santo André (CUFSA)e professor visitante da Universidade Cruzeiro do Sul (UNICSUL). E-mail: evgodoy@terra.com.br

* Doutor em Educação pela Universidade de São Paulo, realizou estágios de pós-doutoramento na Universidade de Sevilha e na École des Hautes Études en Sciences Sociales de Paris. Atualmente é professor livre-docente da Faculdade de Educação da USP. E-mail: vms@usp.br
} 


\section{A LOOK AT CULTURE}

ABSTRACT: This article aims to discuss multiple cultural meanings as well as the necessity for taking culture into account among others to reflect on issues related to such ideas as power, resistance and politics, which do not originate from curriculum theories rather than drawn on by them. The importance of culture is to be highlighted under discussion of contemporaneity issues based on the premise that culture comprises of significance systems which provide a sense of meaning for human actions, therefore, they might be ours or otherwise. It can, thus, be inferred that any social action is also cultural and that, consequently, social practices that express, communicate and produce meaning are discursive practices of significance. Ideas of authors who investigate the thematic curriculum are borrowed to support the relevance of culture in discussions centered on education, school, course units, relations of power, resistance and politics Keywords: Practices of signification. Culture. Curriculum. Power.

\section{INTRODUC̣ÃO}

Compartilhamos do pensamento de Hall (1997) sobre o fato de que "toda ação social é cultural, que todas as práticas sociais expressam ou comunicam um significado e, neste sentido, são práticas de significação", ou seja, toda prática social tem uma dimensão cultural, da mesma forma que as práticas política e econômica, também possuem uma dimensão cultural. Conforme Neto (2003), não é "tomar a cultura como uma instância epistemologicamente superior às demais instâncias sociais, mas sim tomá-la atravessando tudo aquilo que é do social". Segundo Moreira \& Candau (2003), "aceitando-se esse ponto de vista, não há como se negar a estreita relação entre as práticas escolares e a(s) cultura(s)".

Para Neto (2003), atualmente as questões culturais têm recebido grande atenção, nas mais diferentes esferas, acadêmicas, políticas, cotidiana e mesmo econômica, crescendo, assim, a importância da cultura para refletir sobre o mundo contemporâneo. No campo educacional, não foi diferente, pois, conforme Giroux (1986), a cultura é um construto central para a compreensão das relações complexas entre a escolarização e a sociedade dominante.

Segundo Giroux (1986), nas revisões feitas na teoria marxista, na década de 1970, o capital cultural passa a ocupar um lugar privilegiado que, antes, era ocupado, unicamente, pelo capital econômico. 
A centralidade da cultura não significa que ela é uma dimensão epistemologicamente superior às demais dimensões sociais, tais como a política, a econômica, a educacional, mas que atravessa toda e qualquer prática social. Essa centralidade indica "a forma como a cultura penetra em cada recanto da vida social contemporânea, fazendo proliferar ambientes secundários, mediando tudo". (HaLl, 1997, p. 5).

Para Hall (1997), a cultura sempre foi importante nas ciências humanas e sociais, pois os estudos das linguagens, da literatura, das artes, entre outros, sempre fundamentaram o tema, embora não fosse trivial o entendimento de que esses estudos compusessem um conjunto diferenciado de significados, ou seja, uma cultura, na concepção deste autor. Já para as ciências sociais, em particular, para a Sociologia, o diferencial da ação social, ou melhor, do comportamento de um indivíduo, ou grupo, é que a cultura demanda e é importante para o significado.

São estes sistemas ou códigos de significados que, segundo Hall (1997), dão sentido às nossas ações, permitem-nos interpretar ações alheias e, quando tomados em seu conjunto, formam as nossas culturas, asseguram que toda ação social é cultural, que as práticas sociais imbuídas de significado são práticas de significação.

Assim, recuperaremos significados de cultura, privilegiando a discussão em torno da centralidade da cultura, ainda que ela seja reconhecida no âmbito teórico há muito tempo; nas práticas escolares, objeto de nossa análise, verifica-se que tem função retórica. Reconhecemos que os significados de cultura extrapolam os propostos neste artigo, no entanto, nossa intenção foi trilhar um caminho que nos conduziria à centralidade da cultura e à sua pertinência para tratar de questões relacionadas ao campo do currículo e, consequentemente, aos saberes produzidos nos intramuros da escola.

\section{A CONCEPCฺÃO NORMATIVA DE CULTURA}

Cuche (2002) considera que a invenção do conceito de CULTURA se deu pós-evolução semântica da palavra CULTURA, que ocorreu na língua francesa no século XVIII, e só depois se difundiu, por empréstimo linguístico, às línguas alemã e inglesa. O termo "cultura" no sentido figurado começa a ser utilizado, com mais frequência, no século XVIII, inicialmente, seguido de um complemento, "cultura das artes", "cultura das letras", "cultura das ciências", como se fosse necessário que a coisa cultivada estivesse explicitada; em seguida, para designar a "formação", a "educação" 
do espírito; e posteriormente, num movimento inverso, deixa de ter o significado de "cultura" como ação (ação de instruir) e passa a "cultura" como estado (estado do espírito cultivado pela instrução, estado do indivíduo que tem cultura).

Segundo Cuche (ibid.), a "cultura" no século XVIII é sempre empregada no singular, o que reflete o universalismo e o humanismo dos filósofos: a cultura é própria do Homem, além de toda a distinção de povos ou de classes. "Cultura" se inscreve então plenamente na ideologia do iluminismo: a palavra é associada às ideias de progresso, de evolução, de educação, de razão que estão no centro do pensamento da época.

\section{Cultura e Civilização}

Thompson (2009) relata que, no final do século XVIII, a palavra francesa é incorporada ao alemão, grafada primeiramente como Culture, mais tarde, como Kultur.

Cuche (ibid.) afirma que a transposição exata da palavra francesa se deve ao prestígio da língua francesa na Alemanha, por dois motivos - o uso do francês como uma marca distintiva das classes superiores e a influência do pensamento Iluminista. Contudo, a palavra Kultur evoluirá muito rapidamente num sentido mais restritivo que sua homóloga francesa e vai obter um sucesso de público que "cultura" não teria ainda, já que "civilização" era a preferida no vocabulário dos pensadores franceses.

Para Thompson (ibid.), no início do século XIX, a palavra "cultura" era usada como um sinônimo para, ou em alguns casos em contraste com, a palavra "civilização", termo este, usado na França e na Inglaterra no fim do século XVIII para descrever um processo progressivo de desenvolvimento humano, um movimento em direção ao refinamento e à ordem, por oposição à barbárie e à selvageria.

O uso distintivo, na Alemanha, das palavras "cultura" e "civilização" está ligado, segundo Thompson (ibid.) à estratificação social existente na Europa, na época; constatada por Cuche (ibid.) como o distanciamento existente entre os valores da nobreza e da burguesia, na Alemanha, de um lado a intelligentsia burguesa alemã, considera-se culta, por sua atuação no campo da academia, da ciência, da filosofia, da artes e por isso se refugia no campo da Kultur, e do outro, a nobreza é vista como civilizada, mas sem cultura, pela intelligentsia.

Para Thompson (ibid.), a intelligentsia burguesa alemã usava o termo Kultur para expressar a sua posição peculiar, para distinguir-se, em suas realizações, das classes superiores às quais não tinha acesso. 
Para Cuche (ibid.), a intelligentsia burguesa alemã, a nobreza da corte, se ela é civilizada, tem singularmente uma grande falta de cultura. Como o povo simples também não tem esta cultura, a intelligentsia se considera, de certa maneira, investida da missão de desenvolver e fazer irradiar a cultura alemã.

Consideramos importante o fato de que, como descrito por Cuche (ibid.), na Alemanha, às vésperas da Revolução Francesa, não há mais a distinção entre os termos "civilização" e "cultura". O termo "civilização" perde sua conotação aristocrática alemã e passa a evocar a França e, de uma maneira geral, as potências ocidentais; da mesma forma que o termo, a "cultura" deixa de ser marca distintiva da burguesia intelectual alemã no século XVIII, e se converte, no século XIX, em marca distintiva da nação alemã inteira. Os traços característicos da classe intelectual, que manifestavam sua cultura, como a sinceridade, a profundidade, a espiritualidade, vão ser, a partir de então, considerados especificamente alemães.

A ideia alemã de cultura é criada pela classe média que duvida dela mesma, que se sente mais ou menos alijada do poder e das honras e que procura para si uma outra forma de legitimidade social. Estendida à "nação" alemã, ela participa da mesma incerteza, ela é a expressão de uma consciência nacional que se questiona sobre o caráter específico do povo alemão que não conseguiu ainda sua unificação política. [...] a "nação" alemã, [...] procura afirmar sua existência glorificando sua cultura. (Cuche, ibid.,p. 26, 27)

Esta é a razão pela qual a noção alemã de Kultur vai tender, cada vez mais, a partir do século XIX, para a delimitação e a consolidação das diferenças nacionais. Trata-se então de uma noção particularista que se opõe à noção francesa universalista de "civilização", que é a expressão de uma nação cuja unidade nacional aparece como conquistada há muito tempo.

O debate franco-alemão do século XVIII ao século XX é arquetípico das duas concepções de cultura, uma particularista, a outra universalista, que estão na base das duas maneiras de definir o conceito de cultura nas ciências sociais contemporâneas.

Por fim, conforme Thompson (ibid.), o conceito de cultura que emergiu no final do século XVIII e início do século XIX e que foi principalmente articulado pelos filósofos e historiadores alemães pode ser descrito como a "concepção clássica", ou seja,

[...] cultura é o processo de desenvolvimento e enobrecimento das faculdades humanas, um processo facilitado pela assimilação de trabalhos acadêmicos e artísticos e ligado ao caráter progressista da era moderna. (Thompson, ibid, p. 169, 170) 


\title{
A invenção do conceito científico de cultura
}

Conforme Cuche (ibid.), o conceito de "cultura" emerge na Etnologia para pensar o problema da especificidade humana na diversidade dos povos e dos costumes. O uso primitivo da palavra "cultura" nas línguas francesa e alemã tem um sentido normativo; já na Etnologia, o seu uso já puro é exclusivamente descritivo, ou seja, não se trata de dizer o que deve ser a cultura, mas de descrever o que ela é, tal como aparece nas diferentes sociedades humanas.

Segundo Thompson (ibid.), o conceito de cultura tem relação estreita com o desenvolvimento da disciplina Antropologia, que tem como um dos seus principais ramos o estudo comparativo da cultura; devido à diversidade de pressupostos e métodos, adotaremos aqui três concepções de cultura, seguindo o caminho trilhado pelo próprio Thompson que traz duas concepções e desenvolve uma terceira.

\section{A CONCEPCฺ̃̃O DESCRITIVA DE CULTURA}

\section{Tylor e a concepção universalista de cultura}

\begin{abstract}
Cultura ou Civilização, tomada em seu sentido etnológico amplo, é aquele todo complexo que inclui conhecimento, crença, arte, moral, lei, costume e todas as demais capacidades e hábitos adquiridos pelo homem enquanto membro da sociedade. A condição da cultura, entre as diversas sociedades da espécie humana, na medida em que é passível de ser investigada nos princípios gerais, é um tema apropriado para o estudo do pensamento e da ação humanos. (Tylor, apud Thompson, ibid., p.171)
\end{abstract}

Conforme Cuche (ibid.), esta é a primeira definição etnológica de cultura e foi dada pelo antropólogo britânico Edward Burnett Tylor. Trata-se de uma definição descritiva e não normativa que rompe com as definições restritivas e individualistas de cultura: para Tylor, segundo Cuche (ibid), a cultura é a expressão da totalidade da vida social do homem, caracterizando-se por sua dimensão coletiva. A cultura é adquirida e por isso não depende da hereditariedade biológica. Sendo a cultura adquirida, então sua origem e seu caráter são, em grande parte, inconscientes. A palavra "Cultura", na acepção de Tylor, é uma palavra neutra, que permite pensar toda a humanidade.

Thompson (ibid.) afirma que uma das tarefas no estudo da cultura, na abordagem tyloriana é esmiuçar as crenças, costumes etc. - que formam um "todo complexo", característico de uma 
determinada sociedade, diferenciando essa sociedade de outros lugares e épocas diferentes - em suas partes constitutivas e classificá-las e compará-las sistematicamente. Assim, a abordagem tyloriana envolve uma série de pressupostos metodológicos acerca de como a cultura deve ser estudada.

\section{Franz Boas e a concepção particularista de cultura}

Conforme nos indica Cuche (ibid.), a concepção antropológica do "relativismo cultural" é, antes de mais nada, um princípio metodológico, e o seu precursor foi Franz Boas, que considerava que, ao estudar uma cultura particular, era preciso abordá-la sem a priori, aplicar suas próprias categorias para interpretá-las e comparála prematuramente a outras culturas. Com isso, a complexidade de cada sistema cultural só poderia ser atingida se o pesquisador mergulhasse "nas águas profundas" do sistema cultural.

A concepção relativista de cultura desenvolvida por Boas implica que cada cultura é única, específica e representa uma totalidade singular, pois é dotada de um estilo particular expresso por meio da língua, das crenças, dos costumes, da arte e influi sobre o comportamento dos indivíduos. Conforme Cuche (ibid.), Boas pensava que a tarefa do etnólogo era também elucidar o vínculo que liga o indivíduo à sua cultura. Sem dúvida há um vínculo estreito entre o relativismo cultural como princípio metodológico e como princípio epistemológico, levando a uma concepção relativista da cultura.

No fim da sua vida, Boas insistia em outro aspecto do relativismo cultural. Um aspecto que poderia talvez ser um princípio ético que afirma a dignidade de cada cultura e exalta o respeito e a tolerância em relação a culturas diferentes. $\mathrm{Na}$ medida em que cada cultura exprime um modo único de ser homem, ela tem o direito à estima e à proteção, se estiver ameaçada.

\section{A análise funcionalista de cultura}

$\mathrm{Na}$ visão de Malinowski, qualquer cultura deve ser analisada numa perspectiva sincrônica, a partir unicamente da observação de seus dados contemporâneos. Neste caminho, Malinowski propõe o funcionalismo centrado no presente, considerado, por ele, o único intervalo de tempo em que as sociedades humanas podem ser objetivamente estudadas. Malinowski, segundo Cuche (ibid.) era contra o evolucionismo voltado para o futuro e contra o difusionismo voltado para o passado, por isso propôs o funcionalismo centrado no presente. 
Para Cuche (ibid.), Malinowski elabora uma "teoria científica da cultura", muito controvertida, a teoria das "necessidades", para explicar o caráter funcional das diferentes culturas. Nesta teoria, segundo Thompson (ibid.), os fenômenos culturais poderiam ser analisados em termos da satisfação das necessidades humanas.

Para Malinowski, (Cuche, ibid.), o indivíduo tem um certo número de necessidades psicológicas (alimentar-se, reproduzir-se, proteger-se etc.), que determinam imposições fundamentais. A cultura constitui precisamente a resposta funcional a esses imperativos naturais, e esta resposta ocorre por meio da criação de "instituições" que designam as soluções coletivas (organizadas) às necessidades individuais.

Para Cuche (ibid.), as instituições são os elementos concretos da cultura, as unidades básicas de qualquer estudo antropológico, e não os "traços" culturais: nenhum traço tem significação se não estiver relacionado com a instituição à qual pertence. $\mathrm{O}$ funcionalismo se revela pouco apto para pensar as contradições culturais internas, as disfunções e até os fenômenos culturais patológicos. O grande mérito de Malinowski seria, no entanto, demonstrar que não se pode estudar uma cultura analisando-a do exterior, e ainda menos a distância.

\section{A CONCEPC̣ÃO SIMBÓLICA DE CULTURA}

Tanto Tylor quanto Boas e Malinowski fazem parte da concepção descritiva da cultura, concepção esta resumida por Thompson (ibid., p. 173) assim:

[...] a cultura de um grupo ou sociedade é o conjunto de crenças, costumes, ideias e valores, bem como os artefatos, objetos e instrumentos materiais, que são adquiridos pelos indivíduos enquanto membros de um grupo ou sociedade. [...]

Para Thompson (ibid.), o estudo da cultura envolve, pelo menos em parte, a comparação, classificação e análise científica desses diversos fenômenos.

Para Thompson (2009), o uso dos símbolos é um traço distintivo da vida humana e este caráter simbólico tem sido um tema recorrente de reflexão entre os interessados e usuários envolvidos no desenvolvimento das ciências humanas e sociais. No contexto da antropologia, essa reflexão pode ser descrita como a concepção simbólica da cultura, e seu esboço inicial surgiu com Leslie White.

White (2009) considera que o Homem e a cultura são inseparáveis, ou seja, um não existe sem o outro. A explicação para essa afirmação pode ser feita por meio dos símbolos e dos 
significados atribuídos a eles, que é uma capacidade inerente ao Homem. A cultura é, então, realizada pela simbolização.

Para White (2009), o discurso articulado é um recurso extremamente poderoso naquilo que diz respeito à criação, ordenação e regulação de sistemas de parentescos, sistemas políticos e econômicos. Esse discurso articulado é fruto da simbolização. A linguagem, neste contexto, possibilita acumular e transmitir o conhecimento, que, por meio da simbolização e do discurso articulado, cria organizações sociais, instituições econômicas, aperfeiçoa constantemente o uso de ferramentas e forma tradições de conhecimentos e de crenças.

Conforme White (2009), se não fosse a nossa capacidade de construir um discurso articulado, ainda estaríamos vivendo como o Homem de Neandertal, sem organização social e tecnologia humana. A cultura, em termos ideológicos, sociológicos e tecnológicos, depende da simbolização, que depende do discurso articulado. Portanto, a origem da cultura foi consequência do exercício da capacidade humana de atribuir significado aos símbolos (simbolizar). Assim, o papel da cultura para White (2009) é contribuir para uma vida com mais segurança e durabilidade para a espécie humana. O homem é, ao mesmo tempo, animal e ser humano.

Visto que a função da cultura é atender às necessidades do homem para tornar a vida segura e duradoura, podemos dividir essas necessidades em duas classes, quais sejam: as que podem ser satisfeitas com os recursos materiais existentes no mundo exterior e as que não podem ser satisfeitas com eles. A cultura explora os recursos do mundo exterior para fornecer materiais e tornar a vida mais segura, contínua e duradoura. A exploração dos recursos pela cultura se dá ideológica, sociológica e tecnologicamente.

Segundo White (2009), a cultura humana não é homogênea, muito pelo contrário, é tremendamente variada, e essas variações apresentam também uma dimensão temporal, pois uma mesma cultura muda com o tempo. Por exemplo, a cultura do Brasil não é hoje o que era há cem anos. A cultura também muda de lugar para lugar: a cultura do estado de São Paulo não é a mesma da Indonésia, a cultura varia com os povos: a cultura dos aborígenes não é a mesma dos índios do Oiapoque.

Não se pode entender uma cultura sem que se saiba algo sobre o Homem como animal. Compreender a origem e as funções da cultura exige compreender o Homem, portanto há uma relação íntima e necessária entre o Homem, como um tipo de animal e a cultura, considerando-a de forma genérica e como um todo. Portanto, 
a origem e a função da cultura não podem ser entendidas sem que saibamos suficientemente sobre o Homem.

Conforme Thompson (2009), nas últimas décadas, a concepção simbólica da cultura foi colocada no centro dos debates antropológicos por Clifford Geertz, o qual defende que o conceito de cultura seja essencialmente semiótico, diferente do simbólico defendido por White.

Segundo Geertz (2008), o ponto global da abordagem semiótica da cultura é contribuir para se ter mais acesso ao mundo conceptual no qual vivem os sujeitos, de modo a conseguirmos, num sentido amplo, dialogar com eles.

Em torno desta análise, Geertz propõe duas condições para a sua teoria cultural, quais sejam: a primeira condição considera que quanto mais o conhecimento teórico avança, mais a tensão aumenta, ou seja, você "não é seu próprio dono", com isso a sua liberdade de modelar-se em termos de uma lógica interna é muito limitada. "Qualquer generalidade que consegue alcançar surge da delicadeza de suas distinções, não da amplidão"; (Geertz, 2008, p. 17); a segunda condição trata a teoria cultural como não profética, uma vez que a generalização não é construída a partir de um conjunto de observações que tentamos subordinar a uma lei ordenadora, mas sim de inferência, que se inicia a partir de um conjunto de significantes (presumíveis) e depois tenta-se enquadrá-los de forma inteligível. Na cultura, este conjunto de significantes são os atos simbólicos ou conjuntos de atos simbólicos, e o objetivo é a análise do discurso.

Geertz (2008) afirma que a tarefa construída a partir da concepção simbólica da cultura é descobrir as estruturas conceituais que informam os atos dos sujeitos, o "dito" no discurso social, e construir um sistema de análise que permite diferenciar o que é específico dessas estruturas conceituais de outros determinantes do comportamento humano, ou seja, a teoria tem como principal tarefa fornecer um vocabulário no qual possa ser expresso o que o ato simbólico tem a dizer sobre si mesmo, ou seja, sobre o papel da cultura na vida humana.

Segundo Thompson (2009), a obra de Geertz é a mais importante formulação do conceito de cultura que emergiu da literatura antropológica, uma vez que ele reorientou a análise da cultura para o estudo do significado e do simbolismo e destacou a centralidade da interpretação como uma abordagem metodológica.

Contudo, Thompson impõe à teoria de Geertz três dificuldades e fraquezas, dentre as quais nos interessa a que considera que a abordagem teórica de Geertz dá pouca atenção aos problemas de conflito social e de poder. 
$\mathrm{Na}$ abordagem semiótica de Geertz, sua ênfase é mais para o significado do que para o poder, e mais para o significado do que para os significados divergentes e conflitantes que os fenômenos culturais podem ter para indivíduos situados em diferentes circunstâncias e possuidores de diferentes recursos e oportunidades. Portanto, a análise feita por Thompson acerca da concepção simbólica da cultura, especialmente na forma elaborada nos escritos de Geertz, falha ao não dar atenção suficientemente aos problemas de poder e conflito e, mais genericamente, aos contextos sociais estruturados dentro dos quais os fenômenos culturais são produzidos, transmitidos e recebidos.

\section{A CONCEPC̣ÃO ESTRUTURAL DE CULTURA}

Thompson toma como referência o trabalho de Geertz para desenvolver uma abordagem alternativa a respeito dos fenômenos culturais. Essa abordagem busca enfatizar tanto o caráter simbólico dos fenômenos culturais como o fato de tais fenômenos estarem sempre inseridos em contextos sociais estruturados.

Thompson oferece uma característica inicial da sua concepção, definindo a "análise cultural" como:

[...] o estudo das formas simbólicas - isto é, ações, objetos e expressões significativas de vários tipos - em relação a contextos e processos historicamente específicos e socialmente estruturados dentro dos quais e por meio dos quais, essas formas simbólicas são produzidas, transmitidas e recebidas. Os fenômenos culturais, deste ponto de vista, devem ser entendidos como formas simbólicas em contextos estruturados; e a análise cultural como o estudo da constituição significativa e da contextualização social das formas simbólicas. (Thompson, 2009, p.181)

Para Thompson (2009), como formas simbólicas, os fenômenos culturais são significativos tanto para os atores, pois são, rotineiramente, interpretados por eles na sua vida cotidiana, quanto para os analistas, que buscam por meio da interpretação compreender as características significativas da vida social. No entanto, formas simbólicas, para esse autor, inserem-se em contextos e processos sócio-históricos específicos dentro e por meio dos quais são produzidas, transmitidas e recebidas.

A estruturação dos contextos e a estruturação dos processos podem ser caracterizadas, por exemplo, por relações assimétricas de poder, por acesso diferenciado a recursos e oportunidades e por mecanismos institucionalizados de produção, transmissão e recepção 
das formas simbólicas, por isso, ao analisarmos os fenômenos culturais, os contextos, os processos estruturados e a interpretação das formas simbólicas, eles são elucidados.

Thompson, ao desenvolver a concepção estrutural da cultura, preocupou-se em como ocorrem os contextos e processos socialmente estruturados por meio dos quais as formas simbólicas promovem e se inserem. A concepção estrutural da cultura é tanto uma alternativa como uma alteração da concepção simbólica, ou seja, um modo de alterar a concepção simbólica, considerando os contextos e processos socialmente estruturados.

Para ele, a constituição das formas simbólicas leva em consideração os aspectos intencional, convencional, estrutural, referencial e contextual. Em relação ao aspecto intencional, as formas simbólicas são as expressões de um sujeito e para um sujeito; as formas simbólicas são produzidas, construídas e empregadas por um sujeito que tem a intenção de alcançar certos objetivos e propósitos, expressar-se por meio de uma mensagem, que deve ser entendida por outro(s) sujeito(s).

$\mathrm{O}$ aspecto convencional relaciona-se ao fato de que a produção, construção ou emprego das formas simbólicas, bem como a interpretação das formas simbólicas pelos sujeitos que as recebem, refere-se a processos que apresentam como característica a aplicação de regras, códigos ou convenções de vários tipos. O movimento citado não implica que o sujeito tenha consciência das regras, ou que seja capaz de formulá-las, mas que as aplique em situações práticas, como esquemas implícitos ou indiscutíveis para a geração e interpretação de formas simbólicas. Como se refere Thompson (2009), elas fazem parte do conhecimento tácito que os indivíduos empregam no curso de suas vidas cotidianas, criando, constantemente, expressões significativas e dando sentido às expressões criadas por outros.

$\mathrm{O}$ aspecto estrutural das formas simbólicas refere-se ao fato de que elas são construções que exibem uma estrutura articulada, uma vez que consistem de elementos que se colocam em determinadas relações uns com os outros. Thompson (2009) faz distinção entre a estrutura de uma forma simbólica, de um lado (que é um padrão de elementos os quais podem ser discernidos em casos concretos de expressão, em efetivas manifestações verbais, expressões ou textos) e o sistema corporificado de uma forma simbólica particular, de outro (que é uma constelação de elementos [sistêmicos] e existem, independentemente, de qualquer forma simbólica particular, mas se concretizam em formas simbólicas neste sentido). 
Para Thompson (2009), a análise dos traços estruturais e a relação entre estes traços e as características dos sistemas simbólicos são uma parte importante, porém limitada, do estudo das formas simbólicas. A importância se deve ao fato de que o significado transmitido é, normalmente, construído com traços estruturais e elementos sistêmicos de forma que, ao analisá-los, podemos aprofundar a nossa compreensão do significado transmitido pelas formas simbólicas. Já a limitação ocorre porque o significado transmitido pelas formas simbólicas nunca é esgotado por esses traços e elementos e porque negligencia o aspecto referencial das formas simbólicas e a abstrai do contexto sócio-histórico e dos processos em que essas formas estão inseridas.

$\mathrm{O}$ aspecto referencial relaciona-se ao fato de que essas formas são construções que tipicamente representam algo, referem-se a algo, dizem algo sobre alguma coisa. Isso quer dizer que as formas simbólicas ou algum elemento delas podem, num determinado contexto, substituir ou representar um objeto, indivíduo ou situação, bem como num sentido mais específico mediante o qual uma expressão linguística pode, em determinada ocasião de uso, referir-se a um objeto particular.

$\mathrm{O}$ aspecto contextual possibilita às formas simbólicas estar sempre inseridas em processos e contextos sócio-históricos específicos dentro dos quais e por meio dos quais elas são produzidas, transmitidas e recebidas.

Para Thompson (2009), as formas simbólicas mais complexas (discursos, textos, obras de artes etc.) pressupõem uma variedade de instituições específicas dentro e por meio das quais essas formas são produzidas, transmitidas e recebidas. O que elas são, o modo como são formadas, circulam e são recebidas no meio social, bem como o sentido e o valor que têm para os que as recebem depende dos contextos e das instituições que as geram, medeiam e mantêm.

Por fim, a concepção elaborada por Thompson enfatiza a constituição significativa e a contextualização social das formas simbólicas a partir dos pressupostos desenvolvidos por Geertz, articulada com uma abordagem sistemática pelas quais as formas simbólicas estão inseridas em contextos sociais estruturados, examinada a partir dos aspectos intencional, convencional, estrutural e referencial. Após essa discussão acerca da ideia de cultura associada às práticas de significação, pretendemos trazer outros elementos para o debate sobre a centralidade que a cultura alcançou nas diferentes esferas da vida cotidiana. 


\section{A CENTRALIDADE DA CULTURA}

Em nossa concepção, a cultura assume uma posição de destaque para pensar o mundo, a partir de trabalhos seminais (dentre os quais estão o de Raymond Williams), dos Estudos Culturais, na década de 1960. Foi nessa década que, segundo Hall (1997), a virada cultural ${ }^{1}$ adquiriu status elevado nas discussões do cotidiano intelectual e acadêmico e surgiu uma área interdisciplinar, centrada na cultura, denominada "estudos culturais".

A corrente de pensamento seminal dos estudos culturais buscou unir os diferentes sentidos de cultura que estavam se distanciando, ou seja, "cultura (no sentido das artes) define uma qualidade de vida refinada (cultura como civilidade), cuja realização na cultura (no sentido de vida social) como um todo é a tarefa da mudança política." (EAgleTon, 2005, p.34).

Segundo Eagleton (2005), Williams, ao investigar a complexa história da palavra "cultura", identificou três sentidos modernos principais da palavra, associando-os ao cultivo ativo da mente.

Podemos distinguir uma gama desde (i) um estado mental desenvolvido - como em "pessoa de cultura", "pessoa culta", passando por (ii) os processos desse desenvolvimento - como em "interesses culturais", "atividades culturais", até (iii) os meios desses processos - como em cultura considerada como "as artes" e "o trabalho intelectualdo homem. (Williams, 2008, p. 11)

Para Williams (2008), os sentidos de cultura serviram como resultado de formas precursoras de convergência de interesses, das quais se destacam duas principais, frequentemente classificadas como idealista (ênfase no espírito formador) e materialista (com ênfase numa ordem social global), que contribuem fortemente para o estudo das relações entre as atividades culturais e as demais formas de vida social.

Nas obras contemporâneas, as duas formas citadas são revisitadas e assumem definições mais amplas, associadas a um sistema de significações em que, qualquer que seja a ação social, ela é informada, transmitida, apropriada, o que permite certa convergência entre os sentidos antropológico e sociológico da cultura e o sentido mais especializado de cultura como atividades artísticas e intelectuais; dessa forma, o caráter estético e o antropológico se conciliam. Eagleton (2005) considera que a cultura como ideia começa a ser importante em quatro momentos históricos de crise, quais sejam

[...] quando se torna a única alternativa aparente a uma sociedade degradada; quando parece que, sem uma mudança social profunda, a cultura no sentido das artes e do bem viver não será mais nem mesmo possível; quando fornece os 
termos nos quais um grupo ou povo busca sua emancipação política; e quando uma potência imperialista é forçada a chegar a um acordo com o modo de vida daqueles que subjuga. (Eagleton, 2005, p. 42)

Segundo Eagleton (2005), os dois últimos, provavelmente, foram os responsáveis pelo status da centralidade da cultura, ou seja, quando a dimensão política da cultura fortalece-se, a cultura empodera-se.

Para Hall (1997), a centralidade da cultura pode ser investigada a partir do seu aspecto substantivo, que significa a posição de destaque que ocupa a cultura na estruturação organizacional e institucional de uma sociedade, independentemente, do momento histórico e, do seu aspecto epistemológico, que significa o posicionamento da cultura frente às questões conceituais e de conhecimento, acerca de como a cultura analisa, compreende, delineia, transforma, interpreta e conjetura os modelos teóricos e as nossas ações nesse mundo.

\section{Os aspectos substantivos da centralidade da cultura}

No século XX, a cultura assumiu um papel de destaque em relação à estrutura e à organização da sociedade pós-moderna, bem como em relação "aos processos de desenvolvimento do meio ambiente global e à disposição de seus recursos econômicos e materiais. Os meios de produção, circulação e troca cultural, em particular, têm se expandido, através das tecnologias e da revolução da informação.” (HALL, 1997, p. 2)

O acelerado desenvolvimento tecnológico, em particular, da indústria da informação, fez com que a mídia, que tanto é uma parte crítica na infraestrutura material das sociedades modernas, quanto um dos principais meios de circulação das informações nessas sociedades, assumisse um lugar privilegiado e, particularmente, perigoso, na inculcação de ideias, de qualquer tipo, na mente das pessoas. Da mesma forma que a mídia elege um corrupto ou derruba um inocente do poder, ela também aumenta a velocidade com que as informações, econômicas, culturais, políticas, religiosas, esportivas etc. são veiculadas, contribuindo para a obtenção de lucros ou prejuízos.

É um lugar muito poderoso para ser ocupado apenas por um setor da sociedade, pois acreditamos que os que detêm o monopólio da informação ascendem a uma condição privilegiada nas relações de poder, governança.

As tecnologias de comunicação digital e da informação são os novos sistemas nervosos que enredam numa teia sociedades multiculturais e é aqui "que as revoluções da cultura [...] causam 
impacto sobre os modos de viver, sobre o sentido que as pessoas dão à vida, sobre suas aspirações para o futuro - sobre a cultura num sentido mais local". (Hall, 1997, p. 2) O impacto causado pela revolução cultural e informacional nas relações globais contemporâneas nos leva a crer que as lutas pelo poder, cada vez mais, serão efetivadas no campo simbólico e discursivo.

Para o referido autor, a centralidade da cultura indica o modo como a cultura invade e medeia cada "recanto da vida contemporânea". É difícil imaginar algum lugar em que a cultura não aja direta ou indiretamente no dia a dia das diferentes sociedades, sejam elas afortunadas ou não. A cultura não pode ser apenas mais uma peça de peão no tabuleiro de xadrez da governança das sociedades contemporâneas.

A centralidade da cultura também impacta a vida interior das pessoas, pois atua na composição de subjetividade, identidade, na fabricação das diferenças, dos sujeitos participantes da sociedade contemporânea. Isso está relacionado ao fato de que “[...] os significados são subjetivamente válidos e, ao mesmo tempo, estão objetivamente presentes no mundo contemporâneo, em nossas ações, instituições, rituais e práticas." (HALL, 1997, p. 6).

O responsável por isso é o destaque dado à linguagem e ao significado das práticas sociais. A construção das identidades sociais se dá no interior da representação, por meio da cultura, e não fora dela.

Novamente, cabe aqui uma discussão mais pontual em relação às questões de identidade, subjetividade e diferença.

\section{Identidade, subjetividade e diferença}

Segundo Woodward (2009), as identidades passam a ter sentido por intermédio da linguagem e dos sistemas simbólicos que formam o seu sistema de representação, que por sua vez, age simbolicamente para classificar, quantificar, relacionar etc. o mundo e nós mesmos.

Para a autora, a identidade é relacional, depende da existência de algo fora dela para se formar; por isso, ela é marcada pela diferença, que é sustentada pela exclusão, pois se alguém é judeu, não pode ser muçulmano, e vice-versa; a identidade também é marcada por meio de símbolos, ou seja, há uma estreita relação entre a identidade de uma pessoa e as coisas que ela usa, por isso o edifício conceitual da identidade é simbólico, social e material.

Além das dimensões simbólica, social e material, que contribuem para a formação e a manutenção das identidades, há também a dimensão psicológica, a qual está associada à posição e ao compromisso que o indivíduo assume com a sua própria identidade. 
A construção das identidades sociais ocorre no interior da representação, por meio da cultura, e não fora dela, ou seja, as identidades são produzidas pelos sistemas de representação.

A representação inclui as práticas de significação e os sistemas simbólicos por meio dos quais os significados são produzidos, posicionando-nos como sujeito. É por meio dos significados produzidos pelas representações que damos sentido à nossa experiência e àquilo que somos. (Woodward, 2009, p. 17)

Desse modo, as práticas de significação geradoras de significados estão envolvidas também por relações de poder, pois, por meio dos sistemas simbólicos, relatam e dão forma ao processo de incluir e excluir e "fornecem novas formas de se dar sentido à experiência das divisões e desigualdades sociais e aos meios pelos quais alguns grupos são excluídos e estigmatizados. As identidades são contestadas". (WoOdWARD, 2009, p. 19).

De acordo com Woodward (2009), qualquer prática social é simbolicamente marcada, já as identidades são diversas e matizadas, tanto no que se referem aos contextos sociais nos quais elas são vividas quanto nos sistemas simbólicos por meio dos quais são dados sentidos às nossas próprias posições.

No que tange à diferença, ela surge na fabricação das identidades, por meio tanto dos sistemas simbólicos de representação quanto pelas formas de exclusão social e, por isso, a identidade e a diferença são intrinsecamente dependentes.

Essas formas de diferença simbólica e social estabelecem-se, de um modo geral, a partir dos sistemas classificatórios. Segundo a referida autora, estes sistemas aplicam um princípio de diferença a uma população de tal modo que seja possível dividi-la em pelo menos dois grupos mutuamente excludentes. Os sistemas classificatórios, ao organizarem e ordenarem a vida cotidiana das pessoas, produzem os significados. "Segundo Durkheim, se quisermos compreender os significados partilhados que caracterizam os diferentes aspectos da vida social, temos que examinar como eles são classificados simbolicamente." (WoOdWard, 2009, p. 40).

Para Woodward (2009), a identificação, a existência da diferença é, por si só, o componente-chave em qualquer sistema de classificação.

[...] as formas pelas quais a cultura estabelece fronteiras e distingue a diferença é aquilo que separa uma identidade da outra, estabelecendo distinções, frequentemente na forma de oposições [...]. Cada cultura tem suas próprias e distintivas formas de classificar o mundo e é por meio da construção de sistemas classificatórios que a cultura nos propicia os meios pelos quais podemos dar sentido ao mundo social e construir significados. (Woodward, 2009, p. 41) 
Para Hall (1997), estes sistemas classificatórios constituem uma forma de regular, culturalmente, nossas condutas, definindo os limites entre a semelhança e a diferença.

A diferença é marcada por representações simbólicas que atribuem significado às relações sociais, mas a exploração da diferença não nos diz por que as pessoas investem nas posições que elas investem nem por que existe esse investimento pessoal na identidade. (Hall, 1997, p. 54)

Acreditamos que seja aqui o lugar onde reside a subjetividade. Do ponto de vista de Woodward (2009), a subjetividade indica a compreensão de si mesmo, pois reúne os pensamentos e as emoções tanto conscientes quanto inconscientes que definem as concepções, certezas e incertezas que construímos sobre nós mesmos.

Essa subjetividade, inspirada por um contexto social, marcadamente linguístico e cultural, influencia a construção de nossa identidade, ou seja, é o social, o linguístico e o cultural atuando, direta ou indiretamente, em quem somos e como pensamos e agimos, ou seja, os posicionamentos com os quais nos apropriamos e nos subjetivamos constituem nossas identidades.

A subjetividade indicada por Woodward é para Foucault, segundo Larrosa (2008), a experiência de si.

A experiência de si não é senão o resultado de um complexo processo histórico de fabricação no qual se entrecruzam os discursos que definem a verdade do sujeito, as práticas que regulam seu comportamento e as formas de subjetividade nas quais se constitui sua própria interioridade. (Larrosa, 2008, p. 43)

Independentemente, do tipo de conjunto de significados elaborado pelas práticas discursivas, a sua eficácia será medida pela capacidade que ele tem para nos assujeitar. "Os sujeitos são, assim, sujeitados ao discurso e devem eles próprios, assumi-lo como indivíduos que, dessa forma, se posicionam a si próprios." (WoOdward, 2009, p. 55).

Para Woodward (2009), o conceito de subjetividade serve ao propósito de exploração dos sentimentos envolvidos no processo de produção e fabricação da identidade. $O$ conceito explica e justifica as escolhas que fazemos para nos apegarmos a identidades particulares.

Segundo Woodward (2009), a cultura molda a identidade do sujeito por meio das práticas de significação e da construção de uma subjetividade específica, a partir de uma gama de identidades possíveis, regulando, com isso, os tipos de sujeitos que somos. 


\section{Os aspectos epistemológicos da centralidade da cultura}

Segundo Hall (1997), uma revolução conceitual de peso está ocorrendo nas ciências humanas e sociais, extrapolando a ideia de colocar as questões centrais no mesmo patamar, ou melhor, ao lado dos processos econômicos, das instituições sociais e da produção de bens, da riqueza e de serviços.

A "virada cultural" está associada à virada linguística, que tomou a linguagem "como um termo geral para as práticas de representação, e a colocou numa posição de destaque na construção e circulação do significado". (HALl, 1997, p. 9) Para exemplificar: uma árvore existe independentemente da nossa vontade, mas ela só é uma árvore, pois é assim que a classificamos.

Assim, há uma correlação forte entre a "virada cultural" e a virada linguística, "pois a cultura não é nada mais do que a soma de diferentes sistemas de classificação e diferentes formações discursivas aos quais a língua recorre a fim de dar significado às coisas." (HALL, 1997, p. 10).

Hall (1997) considera que a "virada cultural" amplia o entendimento da linguagem para a vida social como um todo e, assim, os processos econômicos, políticos, sociais, por dependerem do significado e consequentemente da maneira como vivemos, nos reconhecemos e nos identificamos, também devem ser compreendidos como práticas culturais, discursivas.

Epistemologicamente, "a centralidade da cultura repousa nas mudanças de paradigma que a "virada cultural" provocou no interior das disciplinas tradicionais, no peso explicativo que o conceito de cultura carrega, e no seu papel constitutivo ao invés de dependente, na análise social." (HALL, 1997, p. 12).

É o conceito de cultura ascendendo a uma categoria mais abrangente de instituições e práticas, sugerindo, com isso, que cada instituição ou atividade social cria e não sobrevive sem seu próprio universo distintivo de práticas de significação, de sua própria cultura. Hoje, falamos de cultura empresarial, escolar, do trabalho, das corporações etc.

Segundo Hall (1997), qualquer prática social, ao produzir significados e interferir nas ações sociais é prática cultural, portanto discursiva.

De acordo com Hall, (1997), tanto o político quanto o econômico, na medida em que são imbuídos de significado, são práticas culturais, isso quer dizer que a dimensão discursiva é condição sine qua non do funcionamento da economia e da política. A economia e a política não seriam práticas de significação sem a cultura ou distante 
dos sistemas de significados e dos discursos. Portanto, a cultura é "[...] uma parte constitutiva do "político" e do "econômico", da mesma forma que o "político e o "econômico" são, por sua vez, parte constitutiva da cultura e a ela impõem limites." (HALL, 1997, p. 13)

\section{Cultura e currículo}

Neste trabalho, destacamos a importância da cultura para discutir as questões da contemporaneidade, a partir da premissa de que a cultura é formada por um conjunto de sistemas de significados que dão sentido às ações humanas, sejam elas as nossas ou as demais, possibilitando o entendimento de que qualquer ação social é cultural e que, por isso, as práticas sociais que expressam, comunicam e produzem significados são práticas de significação, discursivas. Dessa forma, sendo a política, a economia, a educação, o poder entre outros, práticas sociais, produtoras de discursos e significados, elas também possuem uma dimensão cultural. Do ponto de vista da dimensão educacional, que é o nosso objeto de estudo, em consonância com Neto (2004), consideramos que a escola tanto produz quanto reproduz a sociedade em que está inserida.

As práticas de significação e os sistemas simbólicos, constituintes de um sistema de representação, atuam na constituição do sujeito, da sua subjetividade e identidade e na fabricação de formas de diferenças entre os elementos de um mesmo ou distinto grupo social. Essa sujeição é responsável pela produção das diferenças, que são intrínsecas à constituição das identidades, regulando os sujeitos e as suas condutas.

A cultura como aqui entendida produz outras formas de regulação, tais como a normativa, que molda, direciona a nossa conduta e as nossas práticas humanas, tornando nossas ações sociais claras para os outros; e os sistemas classificatórios, por meio da classificação de ações e comparação de condutas e práticas humanas.

A sujeição por meio da cultura é uma forma de poder, à medida que a cultura se torna mais central no debate e na compreensão das questões contemporâneas, ou seja, as questões associadas à política, ao poder, à economia, à educação etc.

As mudanças ocorridas nos campos social e cultural e, principalmente, na percepção da importância da cultura para pensar o mundo contemporâneo, ao exercer sua influência no pensamento da educação escolar, atingiram diretamente um componente crucial da educação, qual seja o currículo, possibilitando tomá-lo como uma arena de luta circundada pela significação e pela identidade. O currículo mantém uma relação muito próxima com o social e o 
cultural. Em consonância com Neto (2004), pode-se afirmar que o currículo é um artefato escolar inventado a partir de ressignificações do mundo social e, consequentemente, do mundo cultural, ou seja, ressignificações do espaço e do tempo.

O currículo é, para nós, uma invenção social, logo uma prática cultural e, por isso, segundo Macedo (2006), está envolto por relações ambivalentes de poder relacionadas ao controle e à resistência, associa-se às práticas discriminatórias, local em que as diferenças são produzidas. Em consonância com Macedo (2006), consideramos que o currículo é um lugar em que as culturas convivem com a diferença.

Partilhamos da ideia de Neto (2002) de que o currículo situa-se na interseção entre a escola e a cultura, pois ele é uma parcela da cultura selecionada, por sua relevância em determinada época e que é trazida para a educação escolar, ou seja, o currículo, para nós, faz parte da tradição seletiva.

Concordamos com Silva (2000) sobre o fato de que o currículo passa a ser visto como um artefato cultural, pois, em termos institucionais, é uma invenção social, uma prática discursiva conectada à produção de identidades culturais e sociais; e em termos de conteúdo, é uma construção social pelo fato de o conhecimento ser um produto criado e interpretado socialmente, uma epistemologia social, conforme enunciado por Popkewitz.

Em consonância com Silva (2000), o currículo e o conhecimento escolar são práticas culturais em que a sujeição e a resistência estão frequentemente presentes, e distintos grupos sociais lutam por sua hegemonia.

Como toda a construção social, o currículo não pode ser compreendido sem uma análise das relações de poder que fizeram e fazem com que tenhamos esta definição determinada de currículo e não outra, que fizeram e fazem com que o currículo inclua um tipo determinado de conhecimento e não outro. (Silva, 2000, p. 140)

Ao posicionarmos o currículo na perspectiva que situa a cultura como uma dimensão central para discutir, interpretar, analisar e conjeturar as questões educacionais, concordamos com o pensamento de Silva (2000) de que as diversas formas de conhecimento são, de certa maneira, valoradas igualmente, ou seja,

[...] não há uma separação rígida entre o conhecimento tradicionalmente considerado como escolar e o conhecimento cotidiano das pessoas envolvidas no currículo. [...] ambos buscam influenciar e modificar as pessoas, estão ambos envolvidos em complexas relações de poder [...] estão envolvidos em uma economia do afeto que busca produzir certo tipo de subjetividade e identidade social. (Silva, 2000, p. 142) 
Olhar o currículo escolar na perspectiva que adota a centralidade da cultura, para nós, pode ser o caminho para conseguir montar o quebra-cabeça dos saberes que devem ser privilegiados na educação escolarizada, quais sejam os saberes produzidos pelas culturas do opressor e do oprimido, ou seja, saberes hibridizados.

Objetivamente, a diminuição da fronteira entre os conhecimentos escolares e cotidianos significa que "todo conhecimento, na medida em que se constitui num sistema de significação, é cultural, [...] está estreitamente vinculado com as relações de poder.” (SiLva, 2000, p. 144).

Os saberes escolares são uma forma legítima de criação de significados, de enunciados, "não estão soltos no mundo, e sim, mais ou menos ligados por outros enunciados, numa série discursiva que institui um regime de verdade fora do qual nada tem sentido". (Neto, 2000, apud. Gabriel, 2010, p. 239-240).

$\mathrm{Na}$ medida em que o saber, seja ele escolar ou não, mantém relação estreita com o significado, ele é uma prática discursiva, logo cultural. Sendo assim, adotamos a definição de Foucault sobre saber, qual seja, "o conjunto de elementos, formados de maneira regular por uma prática discursiva e indispensável à constituição de uma ciência, apesar de não se destinar necessariamente a lhe dar lugar". (Foucault, 2007, p. 204).

Para Foucault (2007), um saber é uma prática discursiva caracterizada por um

[...] domínio constituído pelos diferentes objetos que irão ou não adquirir um status científico; [...] espaço em que o sujeito pode tomar posição para falar dos objetos de que se ocupa em seu discurso; [...] campo de coordenação e de subordinação dos enunciados em que os conceitos aparecem, se definem, se aplicam e se transformam; [...] finalmente, um saber se define por possibilidades de utilização e de apropriação oferecidas pelo discurso.(Foucault, 2007, p. 204)

Conforme nos indica Foucault (2007), o saber não é encontrado somente nas demonstrações, provas e teoremas, mas também em ficções, reflexões, narrativas, regulamentos institucionais e decisões políticas.

Segundo Machado (1979), Foucault introduz nas análises históricas a questão do poder como um instrumento analítico que tem a capacidade de explicar a produção dos saberes.

O poder não é um objeto natural, uma coisa; é uma prática social e, como tal, constituída historicamente. [...] Poder este que intervém materialmente, atingindo a realidade mais concreta dos indivíduos - o seu corpo - e que se situa ao nível do próprio corpo social, e não acima dele, penetrando na vida cotidiana e por isso podendo ser caracterizado como micropoder ou sub-poder (Machado, 1979, p. X e XII) 
A essência dessa análise está no fato de que, o saber e o poder implicam-se mutuamente, pois, de acordo com Machado (1979), não há relação de poder sem a fabricação de saberes, bem como todo saber produz novas relações de poder.

O conhecimento, seja ele científico ou não, segundo Machado (1979), tem a sua existência condicionada ao poder, à fabricação de sujeitos e de domínio de saber.

Acreditamos que a relação dialética entre saber e poder ajuda a mensurar e compreender a dimensão se não exata, mas muito próxima disso, do valor e da importância do conhecimento, seja ele científico ou de outra natureza, na configuração da sociedade contemporânea uma sociedade tecnológica e informacional, em que o capital cultural, por intermédio do imaterial, transforma, cada vez mais, as relações trabalhistas, econômicas, políticas, sociais e culturais.

\section{CONSIDERAÇÕES FINAIS}

Neste artigo, a discussão foi pautada em torno da centralidade da cultura nas questões, envolvendo, sobretudo, a educação escolar, objeto de nossa investigação. Encontramos, na cultura, a justificativa para torná-la o elo entre as diferentes dimensões que interferem na organização curricular, seja ela federal, estadual, municipal, de uma delegacia de ensino, de uma escola, de um professor ou de uma disciplina. As dimensões por nós consideradas como relevantes na organização curricular e transversalizada pela cultura são a social, a política, a econômica e a educativa. Conforme discutido, a centralidade da cultura não significa torná-la uma variável superior às demais variáveis, mas compreender que ela transita em tudo aquilo que se refere ao social, processo esse que foi caracterizado pela virada cultural, conforme indicado por Hall (1997).

As culturas são organizadas por meio de sistemas ou códigos de significação, que dão sentido às nossas e às demais ações. Em virtude disso, qualquer que seja a ação ou prática social, ela é cultural, pois expressa ou comunica significados e, por isso, é prática de significação. A discussão do conceito de cultura, como prática de significação, surge a partir da definição semiótica de cultura sugerida por Geertz.

A abordagem semiótica de cultura, proposta por Geertz (2008), possivelmente, foi motivada pela concepção simbólica de cultura esboçada por White; que considerava que o Homem e a cultura eram inseparáveis, uma vez que a cultura é manifestada 
pela simbolização, e essa, por sua vez, é um tipo de habilidade, competência, inerente apenas aos seres humanos.

Fruto dessa simbolização, o discurso articulado era entendido por White (2009) como um recurso imprescindível na criação, ordenação e regulação de "sistemas sociais", que, veiculado pela linguagem, possibilita acumular e transmitir o conhecimento, seja ele qual for, e permite criar as diferentes instituições sociais e aperfeiçoar, continuamente, o uso de ferramentas, constituir tradições de crenças, concepções e conhecimentos.

Sobessaégide, acultura, doponto de vistaideológico, sociológico e tecnológico, depende da simbolização, consequentemente, do discurso articulado e da linguagem.

Já a concepção semiótica de Geertz assume que, como o Homem está amarrado às redes de significados, tecidas por ele mesmo, logo a cultura é o resultado, ou ainda, o processo de tessitura e as análises feitas, a priori e a posteriori, a partir dessas redes, teias de significados. Consequentemente, a cultura, ou melhor, as culturas são passíveis de investigação, e e, assim, interpretativas, ou seja, em busca de significações, portanto, não experimentais.

A abordagem da cultura, por meio da semiótica de Geertz, auxilia o acesso à parte mais conceitual dos saberes da nossa sociedade, permitindo a nossa inclusão em discussões mais abstratas, logo distantes do senso comum. Neste caso, se tem como objetivo encontrar e selecionar os conceitos que possibilitam denunciar as ações dos indivíduos, ou seja, o "dito" no discurso social e elaborar um sistema analítico que contribuirá na distinção desses conceitos em relação a outros condicionantes do comportamento humano. Traduzindo, a teoria semiótica almeja produzir um sumário que explicite o que o ato simbólico tem a declarar sobre si mesmo, isto é, sobre a finalidade da cultura na vida cotidiana.

A concepção formulada por Geertz reconduziu a análise da cultura para o estudo do significado e do simbolismo, destacando como tendência central, no campo antropológico, a interpretação, como um procedimento metodológico. Todavia, a abordagem semiótica, ao privilegiar mais o significado do que o contexto em que se insere o poder, fracassou. Como levantado por Thompson (2009), a abordagem semiótica de Geertz falhou ao não dar a devida atenção aos contextos sociais estruturados, dentro e por meio dos quais os fenômenos culturais são produzidos, recebidos e repassados.

Nessa direção, Thompson constrói a abordagem estrutural da cultura, apoiada sobre a concepção semiótica, todavia, respeitando, 
em sua análise, o fato de que os fenômenos culturais estão imersos em contextos sociais estruturados - isso quer dizer que a estruturação pode se dar por relações assimétricas de poder, por acesso diferenciado a recursos e oportunidades - sejam elas laborais, sociais ou educativas -, e por dispositivos institucionalizados de produção, transmissão e recepção das formas simbólicas.

Essa concepção é construída em torno da pergunta sobre como se originam e se manifestam os contextos e processos socialmente estruturados por meio dos quais as formas simbólicas são ascendidas e inseridas; e analisada tomando-se como referência os traços intencional, convencional, estrutural, referencial e contextual.

Compreendemos que as abordagens simbólica, semiótica e estrutural da cultura são responsáveis diretamente pela ascensão do status elevado atribuído à cultura, a partir da década de 1960, com a inauguração da área interdisciplinar dos Estudos Culturais, cujos principais colaboradores foram Raymond Williams e Stuart Hall. Desde então, o capital econômico passa a dividir as atenções da sociedade com o capital cultural.

Para Hall (1997), Eagleton (2005) e outros, a ascensão do capital cultural foi devido, principalmente, aos fatos associados à busca pela emancipação política, econômica (em partes) e mesmo social e cultural dos povos até então silenciados. Esses fatos ocorrem, para nós, no instante em que os impérios (metrópoles), para manterem, em certa medida, o seu poder sobre as colônias, se veem obrigados a fazer concessões políticas, econômicas, sociais, entre outras.

A cultura passa a exercer um papel de destaque nas discussões envolvendo a estrutura e a organização da vida cotidiana das pessoas; e os processos de alocação e desenvolvimento de recursos econômicos, materiais e imateriais, portanto, assumem uma posição de destaque para se pensar também as questões da educação escolar, numa perspectiva diferente daquela em que ela é posta a serviço da educação, para que a escola, por meio das suas disciplinas, transmita-a como capital ou herança. Ela assume um papel de destaque, pois toda a prática social, sendo prática discursiva, possui uma dimensão cultural.

Entendemos, com isso, que essa centralidade da cultura nos ajuda a pensar a educação escolarizada, privilegiando mais as identidades do que as diferenças, trazendo para as discussões, entre as paredes das salas de aulas das diferentes disciplinas, a questão da pluralidade cultural, religiosa, racial, sexual, econômica, política etc. Essa possibilidade, para nós, pode ser concretizada se tomarmos o currículo escolar também como uma prática cultural, embebida 
pela negociação de posições contraditórias de controle e resistência. Considerar o currículo escolar na perspectiva da centralidade da cultura pode ser o caminho para se montar o quebra-cabeça dos saberes que devem ser privilegiados na educação escolarizada, procurando estreitar as fronteiras não só entre os conhecimentos das diferentes disciplinas escolares, mas entre esses saberes e os saberes cotidianos.

Enfim, trata-se de hibridizar os discursos sobre cultura, conhecimento, poder e currículo para pensar crítica e pós-criticamente a natureza e função do conhecimento escolar e suas imbricações com questões de cultura e poder. (Gabriel, 2010, p. 240)

\section{REFERÊNCIAS}

APPLE, M. W. Ideologia e currículo. Trad. Vinicius Figueira. 3. ed. Porto Alegre: Artmed, 2006. CUCHE, Denys. A noção de cultura nas ciências sociais. 2. ed. Trad. Viviane Ribeiro. Bauru: EDUSC, 2002.

EAGLETON, T. A ideia de cultura. São Paulo: Editora Unesp, 2005.

FOUCAULT, M. A Arqueologia do saber. 7. ed. Trad. Luiz Felipe Baeta Neves. Rio de Janeiro: Forense Universitária, 2007.

GABRIEL, C. T. Conhecimento escolar, cultura e poder: desafios para o campo do currículo em "tempos pós". In: MOREIRA, A. F.; CANDAU, V. M. (Org.). Multiculturalismo: diferenças culturais e práticas pedagógicas. 4. ed. Petrópolis: Editora Vozes, , 2010. p. 212-248.

GEERTZ, C. A interpretação das culturas. Rio de Janeiro: LTC, 2008.

GIROUX, H. Teoria crítica e resistência em educação: para além das teorias da reprodução. Trad. Ângela Maria B. Biaggio. Petrópolis, RJ: Vozes, 1986.

HALL, S. A centralidade da cultura: notas sobre as revoluções culturais do nosso tempo. Educação e Realidade, Porto Alegre, n. 2, v. 22, p .5, 1997.

LARROSA, J. Tecnologias do Eu e Educação. In: SILVA, T. T. O sujeito da Educaşão. Estudos foucaultianos. Petrópolis: Editora Vozes, 2008. p. 35-86.

MACEDO, E. CURRÍCULO: Política, Cultura e Poder. Currículo sem Fronteiras, Lisboa, v. 6, n. 2, p. 98-113, 2006.

MACHADO, R. Introdução. Por uma genealogia do poder. In: FOUCAULT, M. Microfísica do poder. Trad. Roberto Machado. 26. Ed. Rio de Janeiro: Edições Graal, p. VII-XXIII, 1979.

MOREIRA, A. F. B.; CANDAU, V. M. Educação escolar e cultura(s): construindo caminhos. Revista Brasileira de Educação. São Paulo, n. 23, p. 156-168, 2003.

NETO, A. V. Currículo, cultura e sociedade. Educação Unisinos, Porto Alegre, v. 8, n. ${ }^{\circ}$ 15, p. $157-171,2004$

Cultura e currículo: um passo adiante. In: MOREIRA, A. F. B.; PACHECO, J. A.; GARCIA, R. L. (org.) Currículo: pensar, sentir e diferir. Rio de Janeiro: DP\&A, p. 51-56, 2004. Cultura, culturas e educação. Revista Brasileira de Educação. São Paulo, n. 23, p. $5-15,2003$. 
Currículo e cultura. Contrapontos, Itajaí, ano 2, n. 4, p. 43-51, 2002

SILVA, T. T. Teorias do Currículo: uma introdução crítica. Porto, Portugal: Editora Porto, 2000 THOMPSON, J. B. Ideologia e cultura moderna. Teoria social crítica na era dos meios de comunicação de massa. Petropólis: Vozes, 2009.

WHITE, L. A.; DILLINGHAM, B. O conceito de cultura. Rio de Janeiro : Contraponto, 2009. WOODWARD, K. Identidade e diferença: uma introdução teórica e conceitual. In: SILVA, T. T. Identidade e diferença. A perspectiva dos Estudos Culturais. Petrópolis: Vozes Ltda, 2009. p. 7-72.

\section{NOTAS}

${ }^{1}$ Refere-se a uma abordagem da análise social contemporânea que passou a ver a cultura como uma condição constitutiva da vida social, em vez de uma variável dependente, provocando, assim, nos últimos anos, uma mudança de paradigma nas ciências sociais e nas humanidades, que passou a ser conhecida como "virada cultural. (HaLl, 1997, P. 9).

Recebido: $01 / 04 / 2013$

Aprovado: 09/05/2014

Contato:

Centro Universitário Fundação Santo André Avenida Príncipe de Gales, 821 - Príncipe de Gales Santo Andre | SP | Brasil CEP 09.060-650 